\title{
Nanostructured $\mathrm{CdO}$ thin films for LPG and $\mathrm{CO}_{2}$ gas sensor prepared by spray pyrolisis technique
}

\author{
R. H. Bari*, S. B. Patil \\ Nanomaterials Research Laboratory, Department of Physics, G. D. M. Arts, \\ K. R. N. Commerce and M.D. Science College, Jamner 424 206, Maharashtra, India \\ *Tel.: +919423914198 \\ *E-mail address: rameshbari24@yahoo.com
}

\begin{abstract}
Nanostructured $\mathrm{CdO}$ thin films were deposited by spray pyrolysis techniques at different spray deposition time on glass substrates. Nanostructured $\mathrm{CdO}$ thin films was prepared using $0.05 \mathrm{M}$ of cadmium acetate dehydrate $\left.\left(\mathrm{CH}_{3} \mathrm{COO}\right)_{2} \mathrm{Cd} \cdot 2 \mathrm{H}_{2} \mathrm{O}\right)$ was dissolved in the deionised water. These thin films were annealing in air at temperatures $500{ }^{\circ} \mathrm{C}$ for $60 \mathrm{~min}$. The thickness of the films, crystallite and grain size were observed to increase with the increase in spray deposition time. As prepared thin films were characterized using XRD, FE-SEM and EDAX. The XRD analysis shows that CdO films were cubic structured. The electrical and gas sensing properties of these films were investigated. Prepared nanostructure $\mathrm{CdO}$ thin films show LPG $(\mathrm{S}=1600)$ and $\mathrm{CO}_{2}(\mathrm{~S}=435)$ gas response at different operating temperature. Gas response, selectivity, response and recovery time of the sensor were measured and presented.
\end{abstract}

Keywords: Spray pyrolysis techniques; $\mathrm{LPG}$ and $\mathrm{CO}_{2}$ sensor; nanostructured $\mathrm{CdO}$; gas response

\section{INTRODUCTION}

The preparation of thin films of the size of a nanometer is important because of their potential applications in the various fields of science and technology, including the diverse fields of electronics, optics, space science, aircraft science, defense and other industries [1, $2]$. There are a number of physical and chemical routes for preparing thin films, like pulsed laser deposition, ion beam sputtering, thermal evaporation, vacuum deposition, chemical vapor deposition, co-precipitation, sol-gel, chemical bath deposition etc. Owing into simplicity and inexpensiveness, the spray pyrolysis (SP) technique is a better chemical method at a lower cost for the preparation of thin films with a larger area. Also, it provides an easy way to dope any element in a ratio of required proportion through the solution medium. This method is convenient for preparing pinhole free, homogenous, smoother thin films with the required thickness [3]. During the last decade, a number of authors have employed the spray pyrolysis technique for the preparation of different kinds of nanoparticles.

$\mathrm{CdO}$ is an n-type semiconductor with a rock-salt crystal structure (fcc) and possesses a direct band gap of $2.2 \mathrm{eV}$ [4]. Its high electrical conductivity and high optical transmittance in the visible region of solar spectrum along with a moderate reflective index make it useful for various applications, photodiodes, gas sensors, etc [5, 6]. Undoped, monodoped and dual 
doped $\mathrm{CdO}$ thin films have been prepared by various techniques such as spray pyrolysis [7], dc magnetron reactive sputtering [8], sol-gel [9], mechanochemical method [10] etc. The temperature is an important parameter for gas sensing materials and designing of the sensor. A sufficient degree of crystallinity is required to attain the desired electronic properties necessary for gas sensor application. Gas sensors using transparent $\mathrm{CdO}$ semiconductors to detect different gases have been extensively reported [11-13].

In this work, nanostructure $\mathrm{CdO}$ thin films with different spray deposition time was prepared by spray pyrolysis technique. The present work investigate the effect of thickness on the nanostructure $\mathrm{CdO}$ thin films. Thickness of the films were measured by using a micro gravimetrical method. Crystal structure and sizes were studied from X-ray diffraction. Morphological and elemental compositions were examined by means of FE-SEM and EDAX respectively. Electrical conductivity and gas sensing properties was studied using static gas sensing system. These nanostructure $\mathrm{CdO}$ thin films were tested for sensing different conventional gases and were observed to be most selective and most sensitive to LPG and $\mathrm{CO}_{2}$ at different operating temperature $350{ }^{\circ} \mathrm{C}$ and $250{ }^{\circ} \mathrm{C}$ respectively.

\section{EXPERIMENTAL}

\section{1. Preparation of nanostructured CdO thin films}

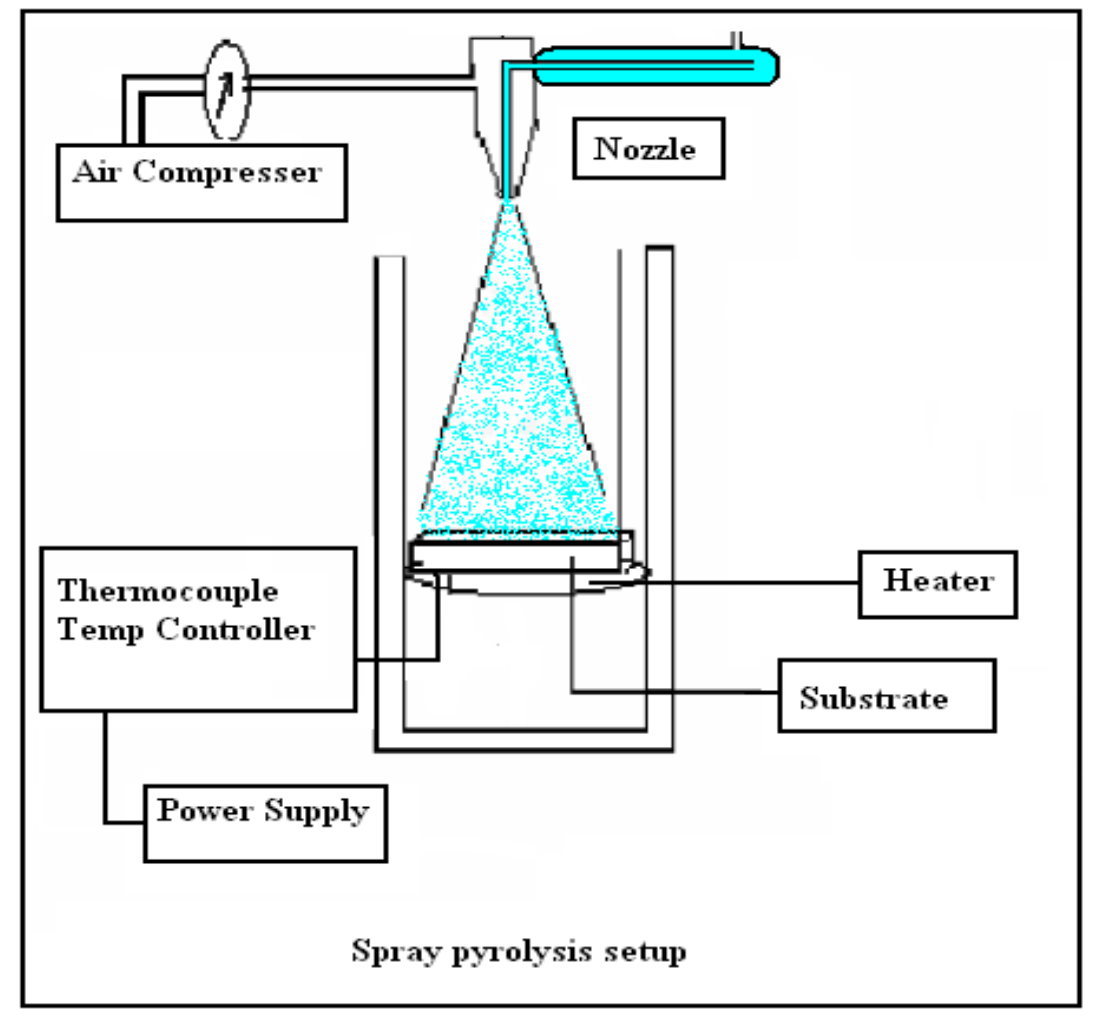

Fig. 1. Spray pyrolysis setup.

Figure 1 shows spray pyrolysis technique for preparation of nanostructured $\mathrm{CdO}$ thin films. Set-up consists of spraying chamber, spray nozzle (gun), compressor for carrier gas, heating system, and temperature indicator. $0.05 \mathrm{M}$ of cadmium acetate dehydrates 
$\left(\mathrm{CH}_{3} \mathrm{COO}\right)_{2} \mathrm{Cd} \cdot 2 \mathrm{H}_{2} \mathrm{O}$ was dissolved in deionised water. Solution was filled in a spray gun and was allowed to spray onto heated glass substrate at constant temperature $300{ }^{\circ} \mathrm{C}$, Thus the films with different spraying time of: $10 \mathrm{~min}, 20 \mathrm{~min}$ and $30 \mathrm{~min}$ were obtained and referred to as S1, S2 and S3 respectively. These thin films were annealing at $500{ }^{\circ} \mathrm{C}$ for 60 min. Process parameters for the spray deposition of nanostructure $\mathrm{CdO}$ thin films are shown in Table 1.

Table 1. Process parameters for the spray deposition of nanostructure $\mathrm{CdO}$ thin films.

\begin{tabular}{|c|c|}
\hline Spray parameter & Optimum value / item \\
\hline Nozzle & Glass \\
\hline Nozzle to substrate distance & $30 \mathrm{~cm}$ \\
\hline $\begin{array}{c}\text { Cadmium acetate dehydrate } \\
\text { solution concentration } \\
\left(\mathrm{CH}_{3} \mathrm{COO}\right)_{2} \mathrm{Cd} \cdot 2 \mathrm{H}_{2} \mathrm{O}\end{array}$ & $0.05 \mathrm{M}$ \\
\hline Spray deposition time & Deionised water \\
\hline Solvent & $7 \mathrm{~min} ., 20 \mathrm{~min}$. and $30 \mathrm{~min}$. \\
\hline Solution flow rate & Compressed air \\
\hline Carrier gas & $300{ }^{\circ} \mathrm{C}$ \\
\hline Substrate temperature &
\end{tabular}

\section{2. Kinetics involved in spray pyrolysis}

The basic principle involved in chemical spray pyrolysis is that when a droplet of the spray solution reaches the hot substrate, owing to the pyrolytic decomposition of the solution, well adherent films are deposited. In this process the solution is pulverized by means of air and arrives on the substrate placed inside the furnace in the form of fine drops known as aerosols which form a thin layer at the substrates.

The spray nozzle with the help of the carrier gases accomplishes the atomization of the chemical solution into aerosols. The temperature of the substrate is maintained at a constant value by using a temperature controlled furnace or hot plate. In general, the films grown at a substrate temperature less than $300{ }^{\circ} \mathrm{C}$ are amorphous in nature.

To get polycrystalline films, one needs to employ higher substrate temperatures or post annealing treatment [14]. The film formation depends upon the droplet lending, reaction and solvent evaporation, which relates to the droplet size. When the droplet approaches the substrate just before the solvent is completely removed, that is the ideal condition for the preparation of the film. 


\subsection{Details of gas sensing system}

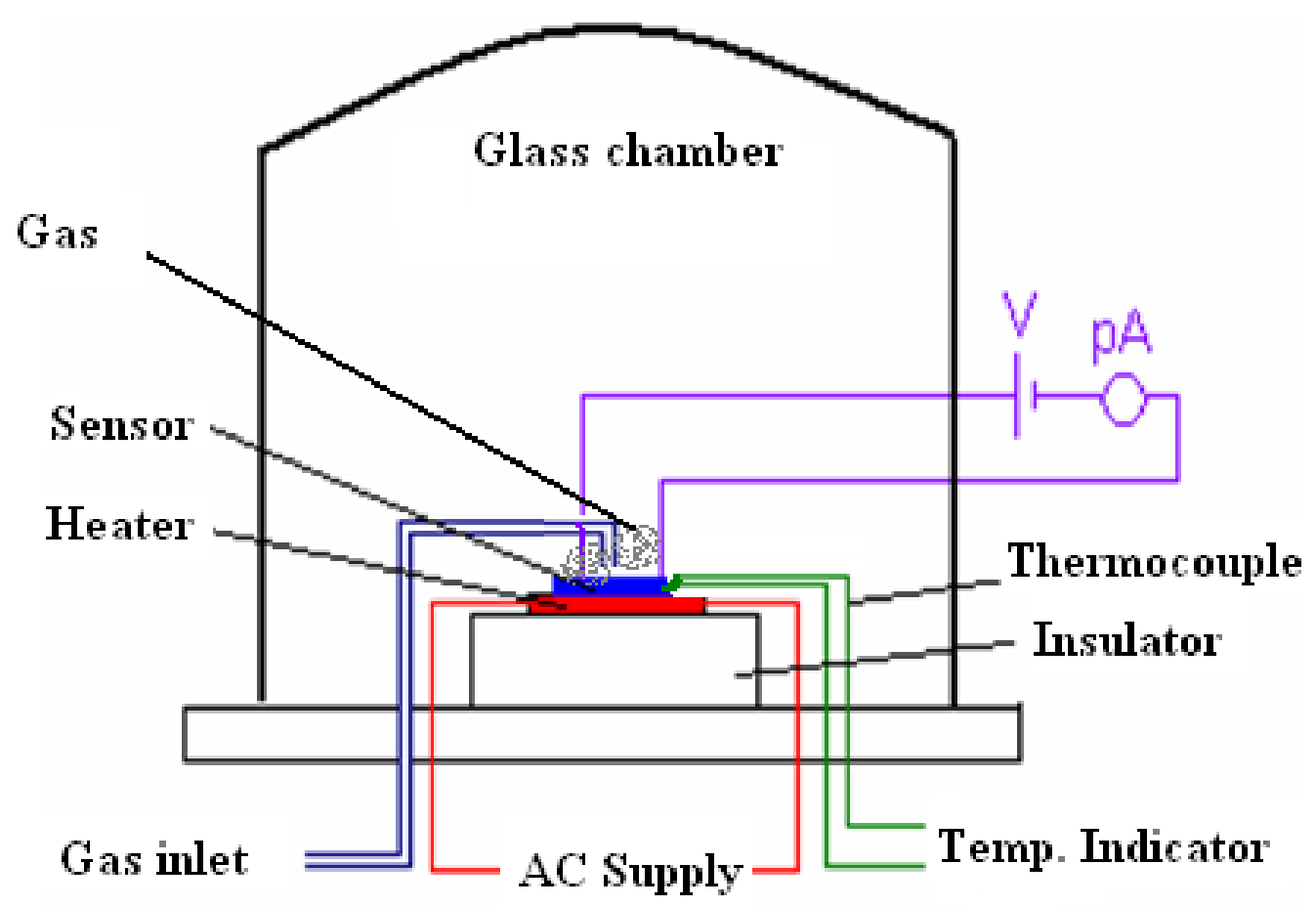

Fig. 2. Block diagram of the static gas system.

The sensing performance of the sensors was examined using 'static gas sensing system'. The static system is built in our laboratory (Fig. 2), which consists sensor element, heating element, gas inject unit, temperature-measuring unit, pico-ammeter, glass dome and steel base plate are major components of static gas sensing system. There are electrical feeds through on the base plate. Heating unit is fixed on base plate. It provides the desired temperature to sensor for its proper functioning. Sample under test can be mounted on the heater. Cromel-alumel ( $\mathrm{Cr}-\mathrm{Al})$ thermocouple is mounted to measure the temperature. The output of thermocouple is connected to temperature indicator. Gas inlet valve fitted at one of the part base plate. Gas concentration $(500 \mathrm{ppm})$ inside the static system is achieved by injecting a known volume of test gas. $(10 \mathrm{~V})$ dc voltage is applied to the sensor element constantly and current meter can measure current.

\section{MATERIALS CHARACTERIZATION}

\section{1. Determination of film thickness}

Film thickness was measured by using a micro gravimetrical method [15] (considering the density of the bulk cadmium oxide). The films were deposited on clean glass slides whose mass was previously determined. After the deposition the substrate was again weighted, determining the quantity of deposited CdO. Measuring the surface area of the deposited film, 
taking account of $\mathrm{CdO}$ specific weight of the film, thickness was determined using the relation:

$$
\mathrm{T}=\mathrm{M}_{\mathrm{CdO}} / \mathrm{A}^{*} \rho * 10^{4}
$$

where $A=$ Surface area of the film $\left[\mathrm{cm}^{2}\right]$

$\mathrm{M}_{\mathrm{CdO}}=$ Quantity of the deposited tin oxide

$\rho=$ Specific weight of CdO.

The values of the film thickness are given in Table 2

\section{2. Structural properties (X-ray diffraction studies)}

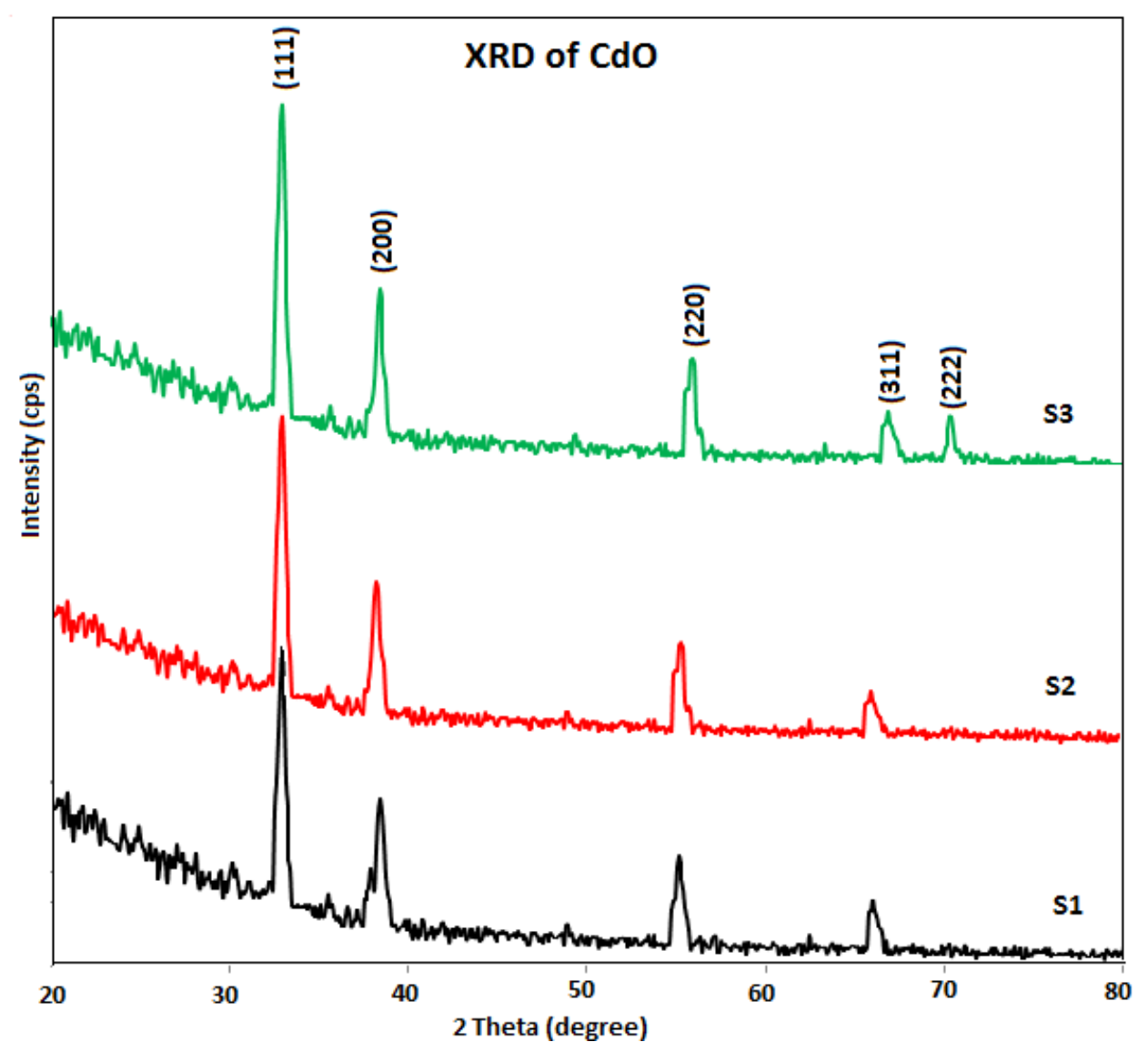

Fig. 3. X-ray diffractogram of nanostructured CdO thin films samples.

As prepared films were characterized by X-ray diffractometer (Philips PW 1730) using $\mathrm{Cu}$ K $\alpha$ radiation $(\lambda=1.5418 \AA)$. Fig. 3 shows the X-ray diffractogram of CdO thin film. The diffraction peaks from various planes are matching well with standard ASTM data for CdO [16]. All the peaks are corresponding to cubic CdO with very strong (111), (200), (220), (311) and (222) peaks. The average crystallite sizes calculated from (111), (200) and (220) peaks, using Scherrer formula and tabulated in Table 2.

$$
D=0 \cdot 9 \lambda / \beta \cos \theta
$$


where, $D=$ Average crystallite size

$\lambda=\mathrm{X}$-ray wavelength $(1 \cdot 5418 \AA)$

$\beta=$ FWHM of the peak

$\theta=$ Diffraction peak position.

\section{3. Microstructure property using FE-SEM}

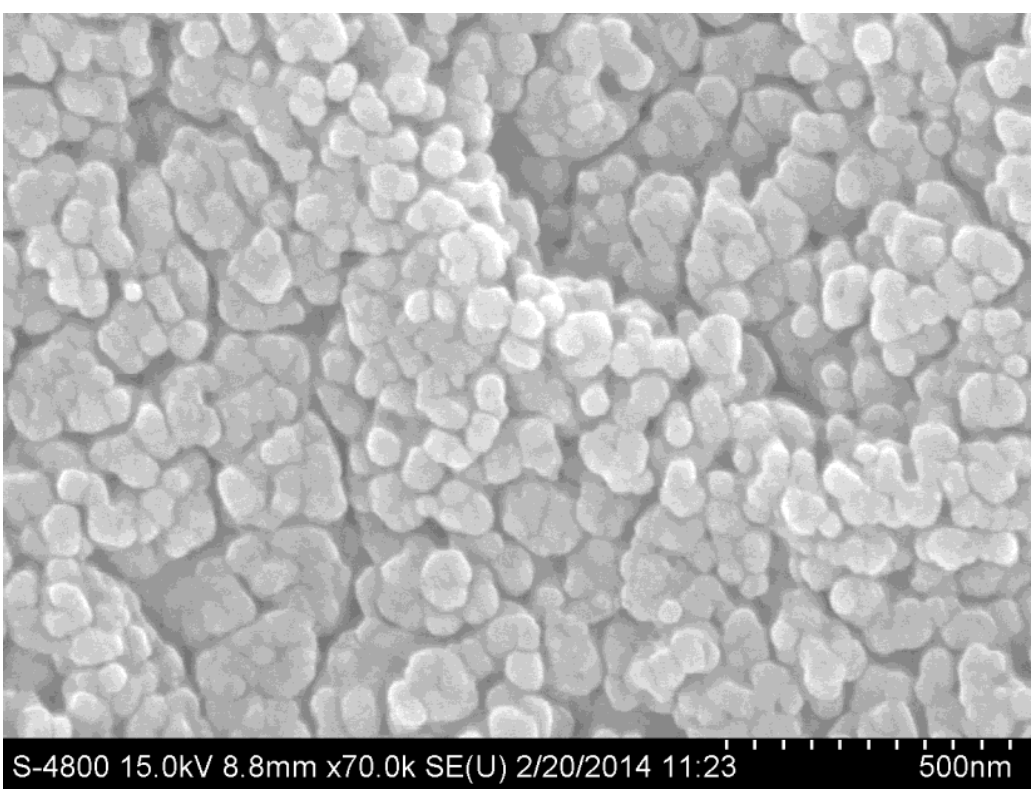

(a)

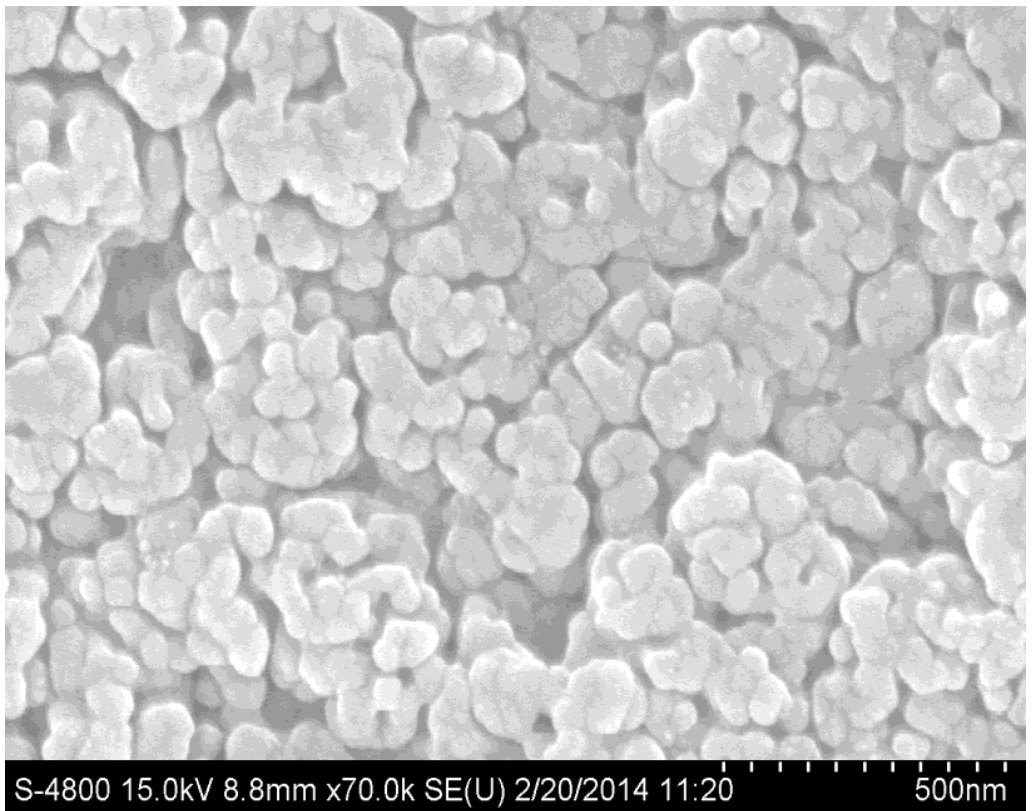

(b) 


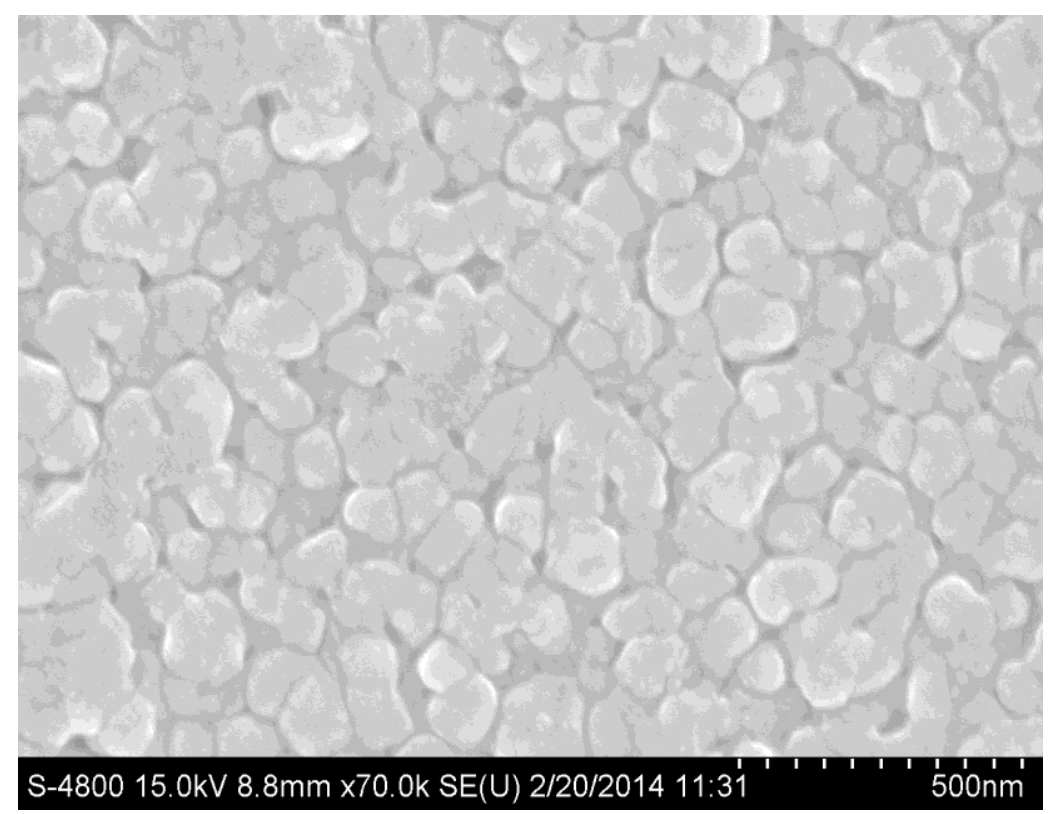

(c)

Fig. 4. FE-SEM images sample S1, S2 and S3.

The surface morphology and quantitative elemental analyses of nanostructure $\mathrm{CdO}$ thin films were studied using field emission scanning electron microscopy (FE-SEM) coupled with EDAX (JEOL JSM - 6360 A)

Fig. 4 (a - c) shows the FE-SEM images of nanostructured $\mathrm{CdO}$ thin film samples $\mathrm{S} 1$, $\mathrm{S} 2$, and $\mathrm{S} 3$ respectively. From micrographs one can see that nanostructured $\mathrm{CdO}$ is formed on the surface of the thin films. Each grain seems to be like spherical of different shape. However, as thickness of the films increases, the spherical shape of grains with an increased grain size were observed. From this behaviour we point out that the grain size increased with increase in thickness of thin films. The observed grain sizes was presented in Table 2.

Table 2. Measurement of spray deposition time, film thickness, crystalline and grain size.

\begin{tabular}{|c|c|c|c|c|}
\hline $\begin{array}{c}\text { Sample } \\
\text { No. }\end{array}$ & $\begin{array}{c}\text { Spray deposition } \\
\text { time (minute) }\end{array}$ & $\begin{array}{c}\text { Thickness } \\
(\mathrm{nm})\end{array}$ & $\begin{array}{c}\text { Crystallite size } \\
\text { from } \\
\text { XRD } \\
(\mathrm{nm})\end{array}$ & $\begin{array}{c}\text { Grain size from } \\
\text { FE-SEM } \\
(\mathrm{nm})\end{array}$ \\
\hline S1 & 10 & 110 & 14 & 16 \\
\hline S2 & 20 & 129 & 17 & 19 \\
\hline S3 & 30 & 147 & 19 & 21 \\
\hline
\end{tabular}

In Table 2 the thickness of the film was varied from 110 to $147 \mathrm{~nm}$. It was found that the thickness of the films crystallite size and grain size increased, with increase in spray deposition time of solution. Crystallinity of the material is direct dependence on the film 
thickness. Crystallinity has been observed to improve with an increase of the film thickness [17]. Moreover, the increase of crystallite size could be attributed to the improvement of the crystallinity and an increase in the cluster formation leading to agglomeration of small crystallites. These agglomerated crystallites coalesce together resulted in the formation of larger crystallites with better crystallinity.

\section{4. Elemental analysis using EDAX}

The quantative elemental composition of the nanostructured $\mathrm{CdO}$ thin film (sample S2) was analyzed using an energy dispersive spectrometer shown in Figure 5.

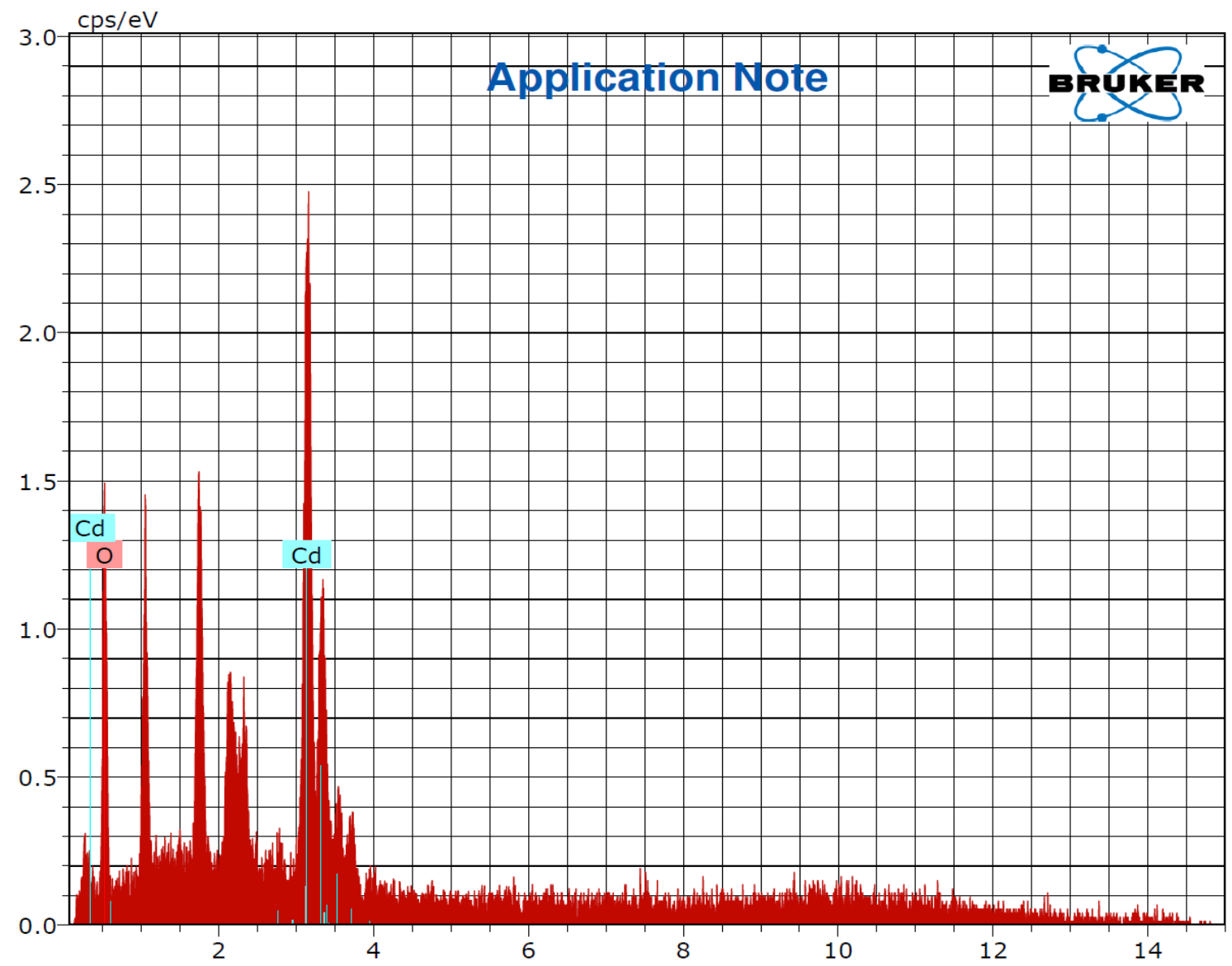

Fig. 5. Elemental analysis of most sensitive nanostructured CdO thin film sample (S2).

Table 3. Elemental compositions of nanostructured $\mathrm{CdO}$ thin films.

\begin{tabular}{|c|c|c|c|c|c|c|}
\hline \multirow{2}{*}{ Element } & \multicolumn{4}{|c|}{ Observed } \\
\cline { 2 - 7 } & \multicolumn{2}{|c|}{ Sample S1 } & \multicolumn{2}{c|}{ Sample S2 } & \multicolumn{2}{c|}{ Sample S3 } \\
\cline { 2 - 7 } & wt \% & at \% & wt \% & at \% & wt \% & at \% \\
\hline \multirow{2}{*}{$\mathrm{Cd}$} & 51.60 & 46.62 & 54.67 & 53.12 & 49.83 & 54.65 \\
\hline
\end{tabular}




\begin{tabular}{|c|c|c|c|c|c|c|}
\hline $\mathrm{O}$ & 48.40 & 53.38 & 45.33 & 46.88 & 50.17 & 45.35 \\
\hline $\mathrm{CdO}$ & 100.00 & 100.00 & 100.00 & 100.00 & 100.00 & 100.00 \\
\hline
\end{tabular}

The quantitative elemental composition of the thin films and the amounts of $\mathrm{CdO}$ analyzed using an energy dispersive spectrometer is represented in Table 3. Stoichiometric compositions of cations (Cd) and anions (O) are 50 and 50 at \%, respectively. The observed compositions of sample were nonstoichiometric proportion.

\section{5. Electrical properties of the sensor}

Electrical and gas sensing properties were measured using a static gas sensing system. The sensor performance on exposure of LPG, carbon dioxide, hydrogen, ammonia, ethanol, chlorine, hydrogen disulphide, nitrogen dioxide, and sulphur dioxide was examined.

\section{5. 1. I-V Characteristics}

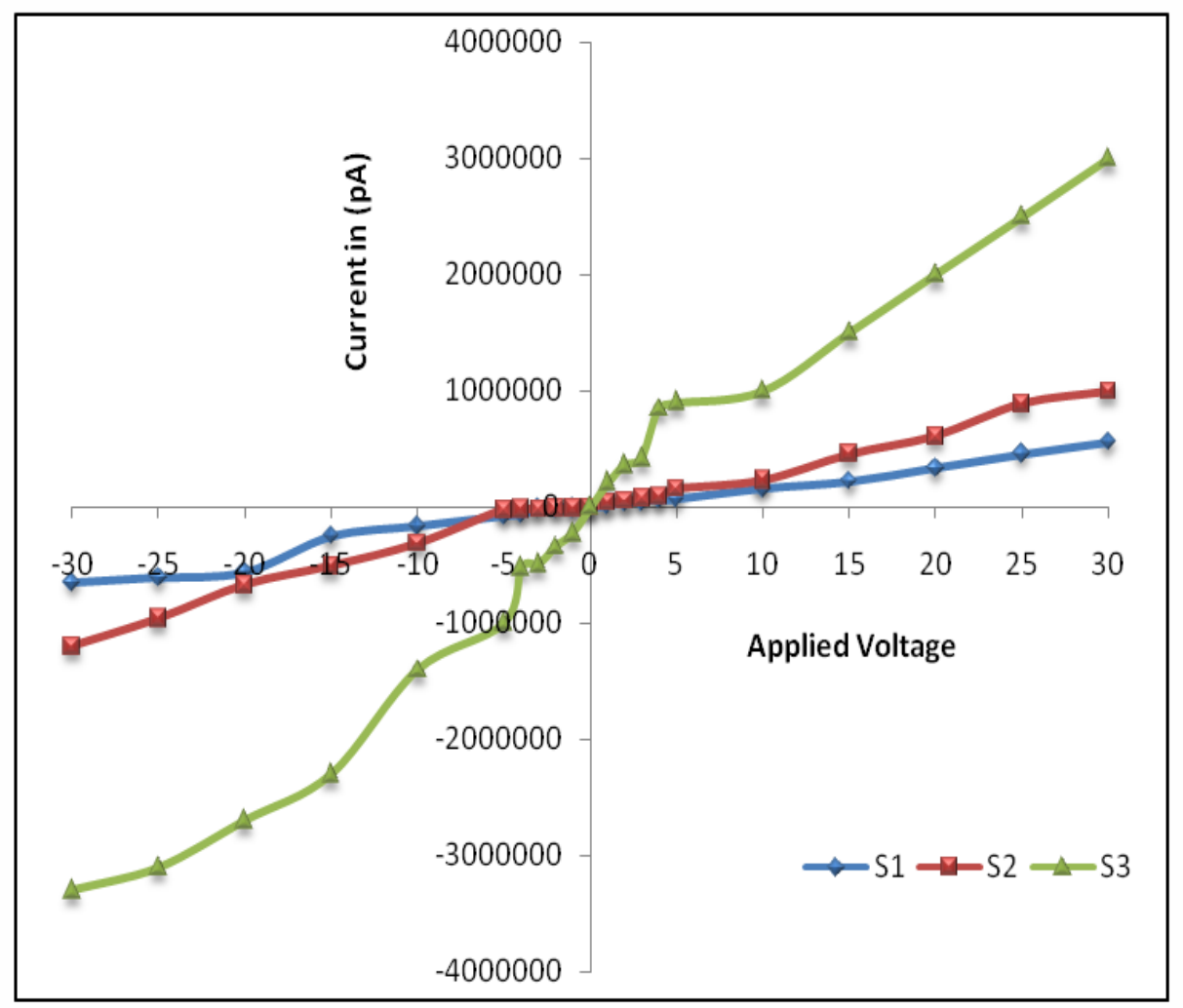

Fig. 6. $\mathrm{I}-\mathrm{V}$ characteristics of nanostructured $\mathrm{CdO}$ thin film sensors.

The contacts were made by silver paste on thin film surface. The configuration was 1.5 $\mathrm{cm} \times 1 \mathrm{~cm}$. Fig. 6 shows the $\mathrm{I}-\mathrm{V}$ characteristics of samples prepared by different spray deposition time. It was observed to be nearly symmetrical in nature indicating ohmic nature of contacts. The non-linear I-V characteristics may be due to semiconducting nature of the films. 


\section{5. 2. Electrical conductivity}

Fig. 7 shows the variation of $\log (\sigma)$ with operating temperature. The conductivity of each sample is observed to be increases with an increase in temperature. The increase in conductivity with increase in temperature could be attributed to negative temperature coefficient of resistance and semiconducting nature of nanostructured $\mathrm{CdO}$.

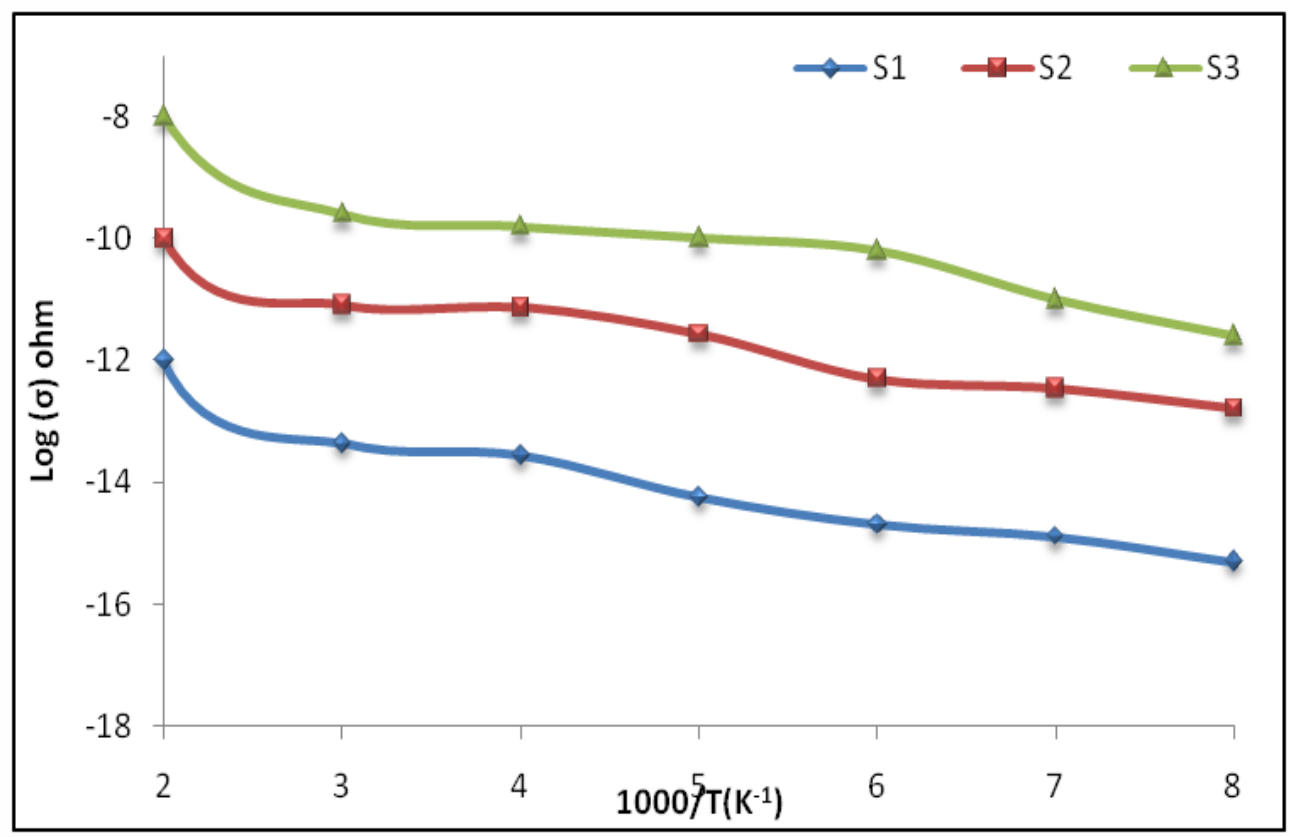

Fig. 7. Variation of $\log (\sigma)$ with operating temperature $\left({ }^{\circ} \mathrm{C}\right)$.

\section{SENSING PERFORMANCE OF THE SENSOR}

\section{1. Measurement of response}

Gas response (S) of the sensor is defined as the ratio of change in conductance to the conductance of the sensor on exposure of target (at same operating conditions).

$$
\mathrm{S}=\mathrm{I}_{\mathrm{g}}-\mathrm{I}_{\mathrm{a}} / \mathrm{I}_{\mathrm{a}}-
$$

where $I_{a}=$ the conductance of the sensor in air $\mathrm{I}_{\mathrm{g}}=$ the conductance on exposure of a target gas.

\section{2. Sensing performance of nanostructured $\mathrm{CdO}$ thin films for LPG}

Fig. 8 shows variation of gas response with operating temperature of samples on exposure of $500 \mathrm{ppm}$ LPG. It is clear from Fig. 8 that the LPG response of sample prepared sample $\mathrm{S} 2$ shows maximum gas response $(\mathrm{S}=1600)$ at $350^{\circ} \mathrm{C}$ as compared to sample $\mathrm{S} 1$ ( $\mathrm{S}$ $=56)$ and sample $\mathrm{S} 3(\mathrm{~S}=89)$ at $350^{\circ} \mathrm{C}$. It is well-known that the response of the metal-oxide semiconductor sensors is mainly determined by the interactions between a target gas and the surface of the sensors [14]. The sensor is also showing high LPG response at operating temperature $350{ }^{\circ} \mathrm{C}$. 


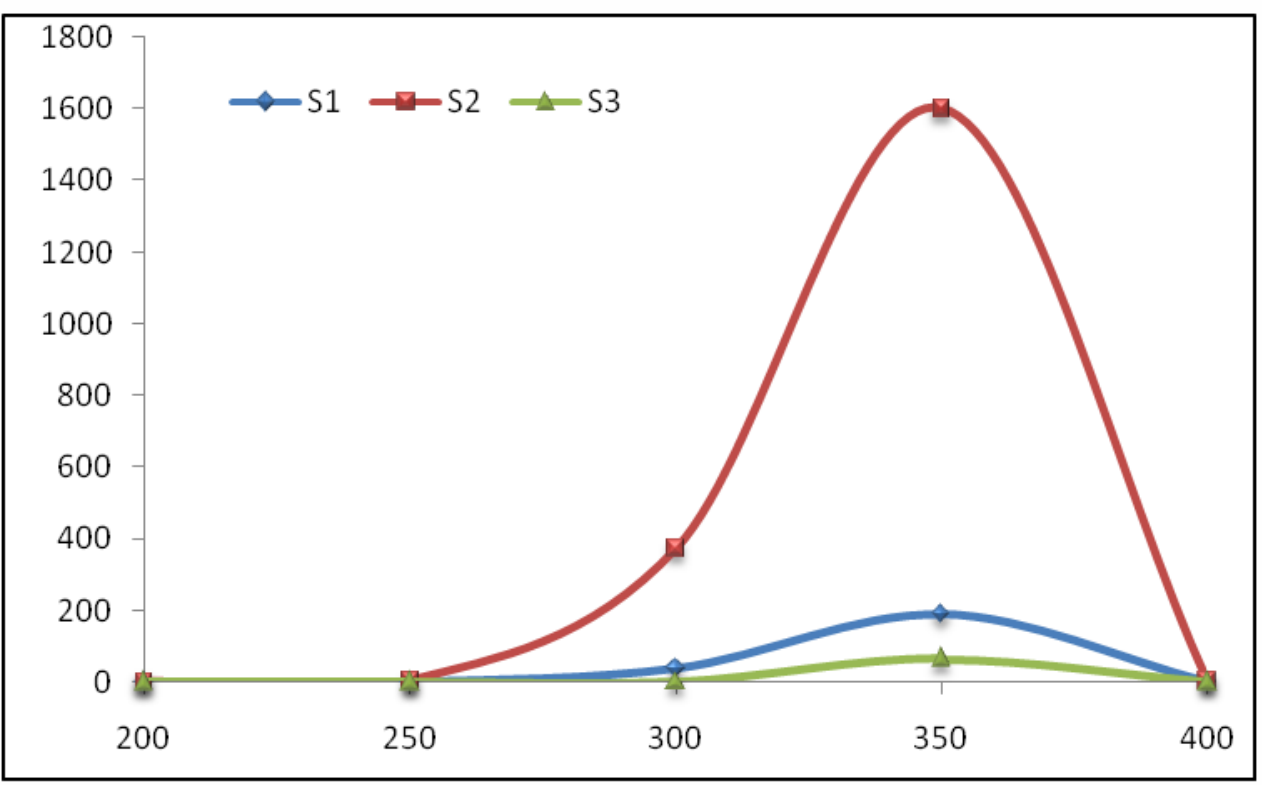

Fig. 8. Variation in response to LPG gas (500 ppm) with operating temperature.

\section{3. Sensing performance of nanostructured $\mathrm{CdO}$ thin films for $\mathrm{CO}_{2}$}

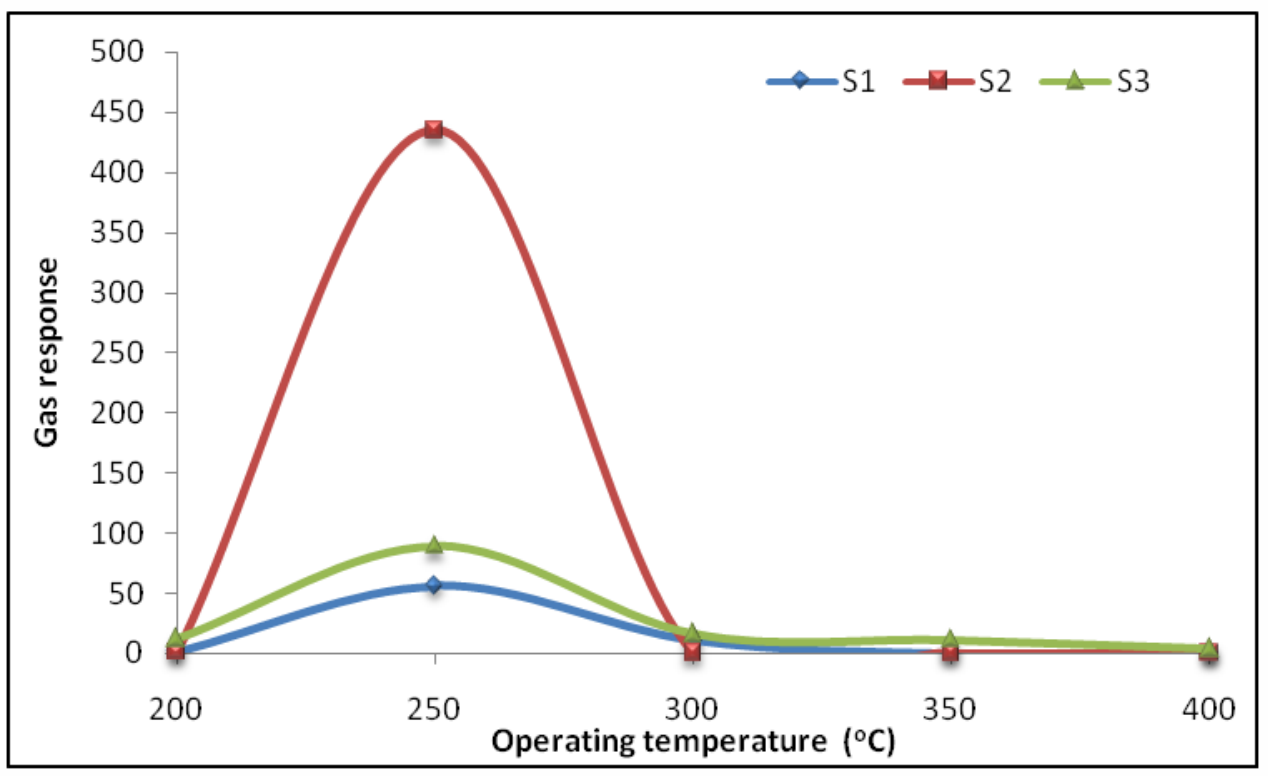

Fig. 9. Variation in response to $\mathrm{CO}_{2}$ gas $(500 \mathrm{ppm})$ with operating temperature.

Figure 9 shows the variation in response with the operating temperature to $500 \mathrm{ppm}$ of $\mathrm{CO}_{2}$ for $\mathrm{S} 1, \mathrm{~S} 2$, and $\mathrm{S} 3$ samples. For all the samples the response increases with increase in operating temperature and reach maximum $(\mathrm{S}=435$ for sample $\mathrm{S} 2)$ at $250{ }^{\circ} \mathrm{C}$ and falls with further increase in operating temperature. Response of sensors depends on two factors, namely: the speed of chemical reaction on the surface of the grains, and the speed of the diffusion of gas molecules to that surface. These are activation processes, and the activation energy of chemical 
reactions is higher. At low temperatures the sensor response is restricted by the speed of chemical reactions $[18,19]$.

At higher temperature the sensor response is restricted by the speed of the diffusion of gas molecules to that surface. At some intermediate temperature the speed values of two processes become equal, and at that point the sensor response reaches its maximum. According to this mechanism for every gas there is a specific temperature at which the sensor response attains its peak value.

\section{4. Selectivity of $\mathrm{LPG}$ and $\mathrm{CO}_{2}$ against various gases at different operating temperature}

Selectivity or specificity is defined as the ability of the sensor to respond to certain gas in the presence of the other gases. Selectivity of nanostructured $\mathrm{CdO}$ thin film sensors is measured at different operating temperature of $350{ }^{\circ} \mathrm{C}$ and $250{ }^{\circ} \mathrm{C}$. Fig. 10 (a) and (b) depicts the bar diagram to indicate LPG and $\mathrm{CO}_{2}$ selective ability of the sensor at different operating temperature.
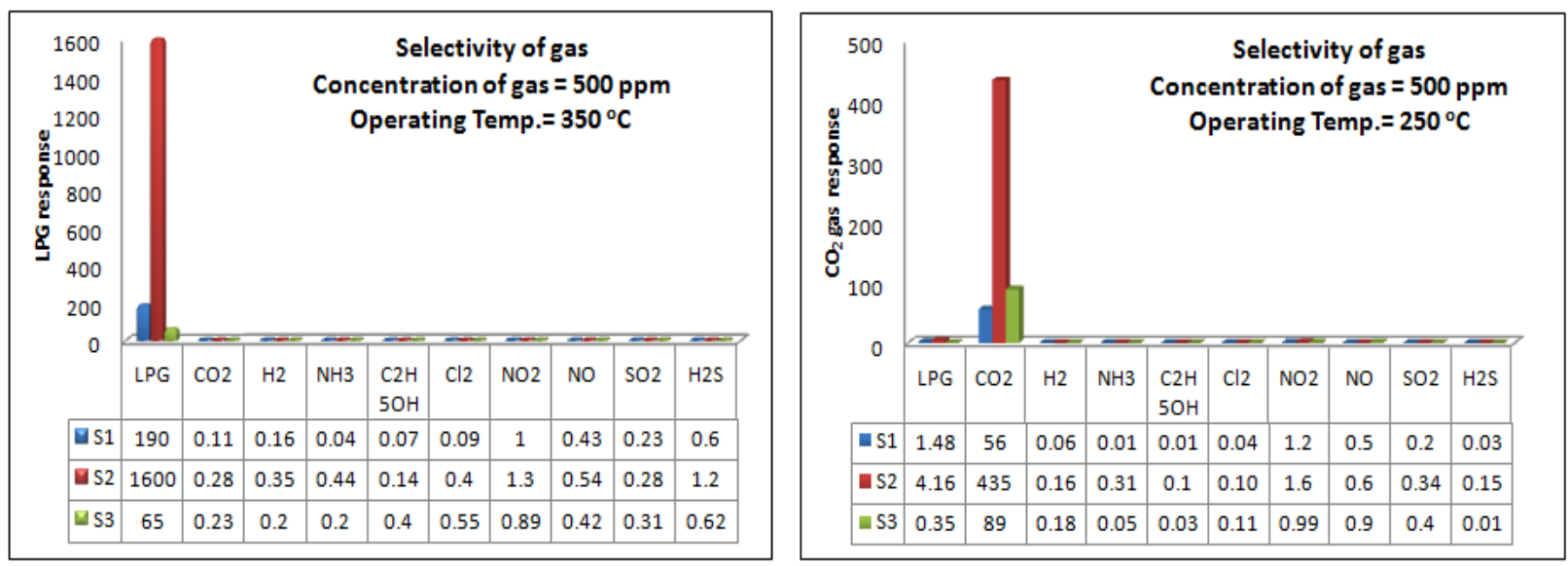

Fig. 10 (a) and (b). Selectivity of nanostructured $\mathrm{CdO}$ thin films for different gases.

It is clear from figure that the responses of all samples to, $\mathrm{H}_{2}, \mathrm{NH}_{3}, \mathrm{C}_{2} \mathrm{H}_{5} \mathrm{OH}, \mathrm{Cl}_{2}, \mathrm{NO}$, $\mathrm{NO}_{2}, \quad \mathrm{SO}_{2}$ and $\mathrm{H}_{2} \mathrm{~S}$ gases are lower as compared to their response to LPG and $\mathrm{CO}_{2}$.Nanostructured $\mathrm{CdO}$ thin films are, therefore, highly selective to LPG and $\mathrm{CO}_{2}$.

The sensor selects a particular gas at a particular temperature. Thus, by setting the temperature, one can use the sensor for particular gas detection. The same sensor could be used for the detection of different gases by operating it at particular temperature for a typical gas. Different gases have different energies for adsorption, desorption and reaction on the metal oxide surface, and therefore, the response of the sensor at different temperatures would depend on the gas being sensed [20].

\section{5. Response and recovery time}

The time taken for the sensor to attain $90 \%$ of the maximum decrease in resistance on exposure to the target gas is the response time. The time taken for the sensor to get back $90 \%$ of original resistance is the recovery time. 


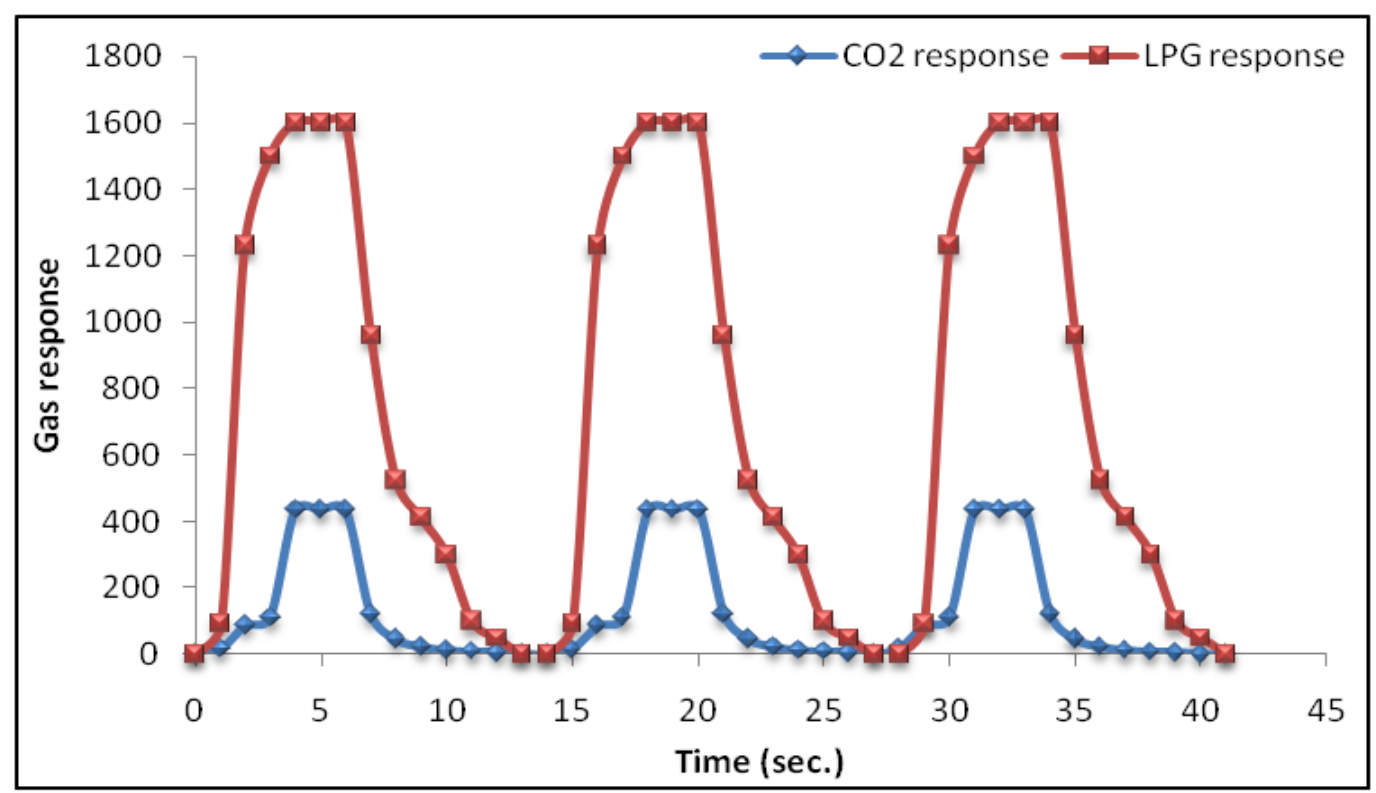

Fig. 11. Response and recovery of the sensor (most sensitive sample = S2).

The response and recovery of the most sensitive thin film S2 sensor on exposure of 500 ppm of LPG and $\mathrm{CO}_{2}$ at different operating temperature $350{ }^{\circ} \mathrm{C}$ and $250{ }^{\circ} \mathrm{C}$ are represented in Figure 11 . The response is quick $(4 \mathrm{~s})$ and recovery is fast $(9 \mathrm{~s})$.

The high oxidizing ability of adsorbed oxygen species on the surface nanoparticles and high volatility of desorbed by-products explain the quick response to LPG and $\mathrm{CO}_{2}$.

\section{DISCUSSION}

\section{1. LPG sensing mechanism}

Gas sensing mechanism is generally explained in terms of change in conductance due to the interaction of test gases with the semiconducting surface as shown in Fig. 12 and 13. The change of conductance is either by adsorption of atmospheric oxygen on the surface and/or by direct reaction of lattice oxygen or interstitial oxygen with the test gases. In case of former, the atmospheric oxygen adsorbs on the surface by extracting an electron from the conduction band, in the form of super oxides or peroxide, which are mainly responsible for the detection of the test gases.

LPG is the composition of carbon and hydrogen. Carbon- Carbon and Carbon hydrogen bonds are quite to strong vander wall's forces . They may break out only at high temperature. The higher temperature dissociates the carbon-carbon and carbon-hydrogen bonds. This dissociation forms the carbon dioxide and $\mathrm{H}_{2} \mathrm{O}$ vapors, which are volatile and may escape easily from the surface of the sensor. The reaction mechanism shown in Fig. 12.

The dissiciability of LPG on activated surface explains quick response, liberating the electrons captured by oxygen ions such as:

$$
\begin{aligned}
& \mathrm{CH}_{4 \text { (gas) }}+4 \mathrm{O}^{-} \text {(film surface) } \rightarrow \mathrm{CO}_{2} \text { (gas) }+2 \mathrm{H}_{2} \mathrm{O}+4 \mathrm{e}^{-} \text {(Cond.bond) } \\
& \mathrm{C}_{2} \mathrm{H}_{6 \text { (gas) }}+7 \mathrm{O}^{-} \text {(film surface) } \rightarrow 2 \mathrm{CO}_{2} \text { (gas) }+3 \mathrm{H}_{2} \mathrm{O}_{\text {(gas) }}+7 \mathrm{e}^{-} \text {(Cond. band) } \\
& \mathrm{C}_{3} \mathrm{H}_{8} \text { (gas) }+10 \mathrm{O}^{-}{ }_{\text {(film surface) }} \rightarrow 3 \mathrm{CO}_{2} \text { (gas) }+4 \mathrm{H}_{2} \mathrm{O}_{\text {(gas) }}+10 \mathrm{e}^{-} \text {(Cond. band) }
\end{aligned}
$$




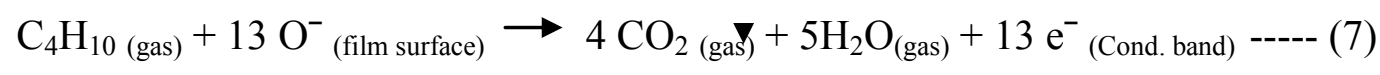

The oxygen reacts with LPG releasing electrons onto the conduction band so, after exposure of LPG, the conductivity of the film increases [18,21]. The high volatility of the byproduct explains the fast recovery of the sensor. The sensor showed better recovery to LPG than other gases.

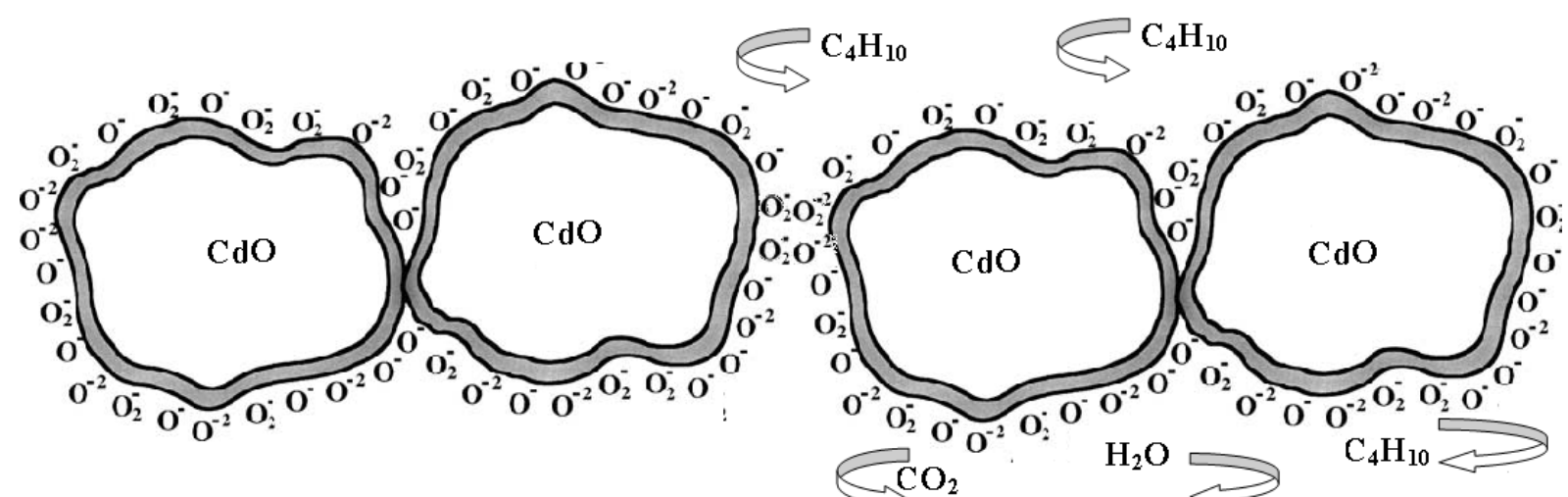

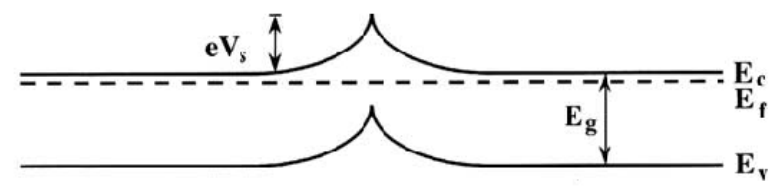

(a) Before exposure of LPG

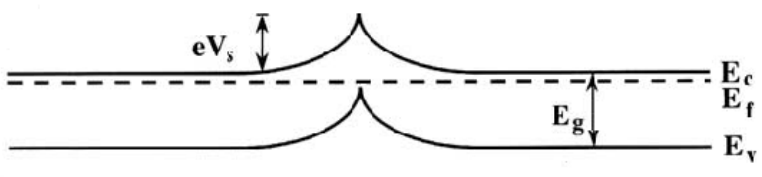

(b) After exposure of LPG

Fig. 12. LPG sensing mechanism of nanostructured $\mathrm{CdO}$ thin film.

\section{2. $\mathrm{CO}_{2}$ sensing mechanism}

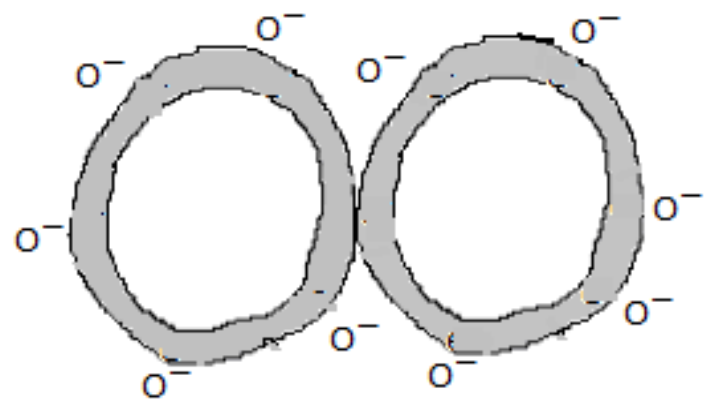

Broad Electron Deplection Layer (a) Before exposure of $\mathrm{CO}_{2}$

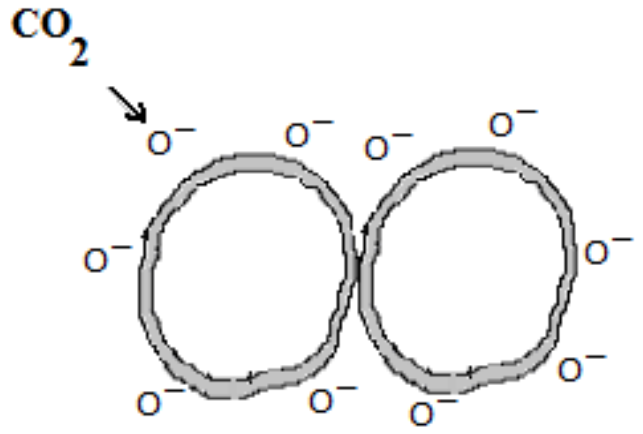

Narrow Electron Deplection Layer

(b) After exposure of $\mathrm{CO}_{2}$

Fig. 13. LPG sensing mechanism of nanostructured $\mathrm{CdO}$ thin film. 
The response of the sensing materials is based on chemisorption, i.e. the exchange of charge between absorbed gases and the metal oxide surface. In air, there are several different negatively charged oxygen adsorbates, such as $\mathrm{O}_{2}^{-}, \mathrm{O}^{-}$, and $\mathrm{O}^{2-}$, which are known to cover the metal oxide surface. The formation of an oxygen adsorbate layer leads to a decrease in the electron density on the metal oxide surface due to charge transfer from the metal oxide to the adsorbate layer.

Fig. 13 shows the $\mathrm{CO}_{2}$ sensing mechanism (Fig. (a) before exposure of $\mathrm{CO}_{2}$ and (b) after exposure of $\mathrm{CO}_{2}$ ) of $\mathrm{CdO}$ thin films, When the oxidation reaction rate of carbon monoxide is much higher than the rates of adsorption and desorption of the reactants, the steady state oxygen coverage depends critically on the relative oxygen and $\mathrm{CO}_{2}$ concentrations in the gas phase. To allow for fast surface reactions the temperature has to be high enough, although not too high, to prevent bulk-surface interactions which can cause long time variations in the sensor parameters [14]. Oxidation of carbon dioxide on a cadmium oxide surface may occur through many different reaction paths, depending on the surface composition, structure and temperature and on adsorbed species. Most of the time, the intermediates and complexes formed during reaction are short-living compounds that are not easily identified. However, in order to understand the overall sensing mechanism of carbon dioxide, it is necessary to know amount of oxygen species are present on the surface and their extent, how does $\mathrm{CO}_{2}$ adsorb on the surface, which reaction paths are possible and which is the rate of each step, how other elements may interfere in the reaction and if they are present.

\section{CONCLUSIONS}

Nanostructured $\mathrm{CdO}$ thin films could be prepared by simple and inexpensive air assisted spray pyrolysis technique.Thickness of the films, crystallite and grain size were observed to be increases with increase in spray deposition time of solution. Surface morphology and elemental analysis confirmed that the as-prepared $\mathrm{CdO}$ thin films was nanostructured and nonstoichiometric in nature. Sensors in present work showed improved LPG and $\mathrm{CO}_{2}$ response at different operating temperature. The sensor has good selectivity to LPG and $\mathrm{CO}_{2}$ against $\mathrm{H}_{2}, \mathrm{NH}_{3}, \mathrm{C}_{2} \mathrm{H}_{5} \mathrm{OH}, \mathrm{Cl}_{2}, \mathrm{NO}, \mathrm{NO}_{2}, \mathrm{SO}_{2}$ and $\mathrm{H}_{2} \mathrm{~S}$ gases. The nanostructured $\mathrm{CdO}$ thin films exhibits rapid response-recovery which is one of the main features of this sensor.

\section{ACKNOWLEDGEMENTS}

The authors are thankful to the University Grants Commission, New Delhi for providing financial support. Thanks to Principal, G. D. M. Arts, K. R. N. Commerce and M.D. Science College, Jamner, for providing laboratory facilities for this work.

\section{Reference}

[1] H. Kamal, Thin solid films 483 (2005) 330.

[2] F. Iacomi, Journal of optoelectronics and advanced material 8 (2006) 266.

[3] P. S. Patil, Material Chemistry and Physics 59 (1999) 185.

[4] M. Ortega, G. Santana, A. Morales-Acevedo, Solid State Electron 44 (2000) 1765. 
[5] R. Ferro, J.A. Rodriguez, Sol. Energy Matter. Sol. Cells 64 (2000) 363.

[6] Mahdi H. Suhail, Issam M. Ibrahim, G. Mohan Rao, Journal of Electron Devices 13 (2012) 965.

[7] O. Vigil, F. Cruz, A. Morles-Acevedo, G. Contreras-Puene, L. Vaillant, G. Santana, Matter. Chem. Phys. 68 (2001) 249.

[8] T.K. Subramanyam, S. Uthanna, B. Srinivasulu Naidu, Materials Letters 35 (1998) 214.

[9] H. Hobert, B. Seltmann, Journal of Non-Crystalline Solids 54 (1996) 195.

[10] A. Tadjarodi, M. Imani, Materials Letters 65 (2011) 1025.

[11] M. G. Ambia, M.N. Eslam, M.O. Hakim, Sol. Energy Mat. Sol. Cells. 28 (1992) 103.

[12] H.A. Mohamed, H.M. Ali, Journal of Science Technology Advanced Material 9 (2008) 025016.

[13] M. Mahaboob Beevia, M. Anusuyab, V. Saravananc, International Journal of Chemical Engineering and Applications 1 ( 2010) 151.

[14] R. H. Bari, S. B. Patil, A. R. Bari, Optoelectronics and advanced materials-rapid communication 6 (2012) 887.

[15] S.D. Sartale, C.D. Lokhande, Materials Chemistry and Physics 21 (2001) 101.

[16] ASTM data for $\mathrm{CdO}$ [05-0640].

[17] Chang J. F., Kuo H. H, Leu I. C, Hon M. H., Sensors and Actuators B 84 (2002) 258.

[18] L.A. Patil, A.R. Bari, M.D. Shinde, Vinita Deo and M.P. Kaushik, Sensors and Actuators B: Chemical 161 (2012) 372.

[19] L. A. Patil, A.R.Bari, M.D. Shinde, Vinita Deo, Sensors and Actuators B: Chemical 149 (2010) 79.

[20] R.R. Salunkhe, D.S. Dhawale, D.P. Dubal, C.D. Lokhande, Sensors and Actuators B 140 (2009) 86.

[21] L.A. Patil, A.R. Bari, M.D. Shinde, Vinita Deog, Sensor Review 30 (2010) 290. 